\title{
Applying biometry to increase productivity in rural and under-developed areas and maximize the potential of local natural resources for global benefit
}

\begin{abstract}
Based on the theme of the 2018 LAMIPISA 5th International Conference that was focused on the poverty in the continent of Africa it was considered important an effort to be undertaken in presenting some basic ideas about the ways of possible helps for the improvement required. Among these the science of biometry could probably offer its contribution to the conference's aim. It is because it is true that there is a great need for the world's second largest and second most-populous continent to succeed in reaching the right that it deserves.

Biometry is the science of the application of mathematical and statistical methods in the biological, agricultural and medical research, in order to reach valid interpretations of biological observations and the right conclusions when evaluating biological experiments. It offers the tools for obtaining valid answers to important research questions which can assist in identifying the optimal biological approaches for achieving the highest levels of the results aimed in various social, climatic and environmental conditions. Answering such questions has the potential to guide the development of rural and under-developed areas, ensure food security, promote local growth, reduce poverty and migration, and create jobs through the use of local natural resources and intensification of sustainable agricultural production and processing.
\end{abstract}

However, this study shows the scarcity of methodologically robust agricultural, environmental and medical research, according to the biometric principles in such under-developed areas, where one can argue is most needed for economic growth, poverty reduction and migration solution.

International Biometric Society-IBS is the international scientific society which serves the science of biometry globally. The main aim of IBS is to promote the development and application of biometric methods. There is a need to focus such work on areas which are under-represented in the biological research field. Such an approach will help towards developing adaptive agricultural techniques, building capacity, maximizing the global agricultural potential, and efficiently using domestic natural resources. It may also assist towards solving some of the major global challenges associated with increasing urbanization, human migration, and climate change.

Keywords: biometry, under-developed rural areas, productivity increase, global benefit
Volume 7 Issue 6 - 2018

\author{
Stergios Tzortzios \\ University of Thessaly, Greece
}

Correspondence: Stergios Tzortzios, University of Thessaly, Greece, Email stzovtzios56@gmail.com

Received: October 16,2018 | Published: November 30, 2018

\section{A general introduction}

It is reported by FAO that between now and 2050, the world's population will increase by one-third. Most of these additional 2 billion people will live in developing countries. At the same time, more people will be living in cities. If current income and consumption growth trends continue, FAO estimates that agricultural production will have to increase by 60 percent by 2050 to satisfy the expected demands for food and feed. Agriculture must therefore transform itself if it is to feed a growing global population and provide the basis for economic growth and poverty reduction. Climate change will make this task more difficult under a business-as-usual scenario, due to adverse impacts on agriculture, requiring spiraling adaptation and related costs.

To achieve food security and agricultural development goals, adaptation to climate change and lower emission intensities per output will be necessary. This transformation must be accomplished without depletion of the natural resource base. Climate change is already having an impact on agriculture and food security as a result of increased prevalence of extreme events and increased unpredictability of weather patterns. This can lead to reductions in production and lower incomes in vulnerable areas. These changes can also affect global food prices. Developing countries and smallholder farmers and pastoralists in particular are being especially hard hit by these changes. Many of these small-scale producers are already coping with a degraded natural resource base. They often lack knowledge about potential options for adapting their production systems and have limited assets and risk-taking capacity to access and use technologies and financial services.

\section{Discussion}

In the first call of the 2018 LAMIPISA 5th International Conference 
the invitations were addressed to anyone interested in the welfare and economic development in general and Africa in particular. The focus is on addressing the distressful economic situation and poverty on the continent. Based on this, this paper has undertaken an effort to present some ideas on the importance of life sciences-as the subject of the science of Biometry- and more particularly one of their main sectors which is the field of agriculture.

Any research in life sciences is proposed to answer a scientific question we might have. To answer this question with a high certainty, we need accurate results. The correct definition of the main hypothesis and the research plan will reduce errors while taking a decision in understanding a phenomenon. The research plan might include the research question, the hypothesis to be tested, the experimental design, data collection methods, data analysis perspectives and costs evolved. It is essential to carry the study based on the three basic principles of experimental statistics: randomization, replication, and local control.

Life sciences discoveries are helpful in improving the quality and standard of life, and have applications in health, agriculture, medicine, and the pharmaceutical and food science industries. The research question will define the objective of a study. The research will be headed by the question, so it needs to be concise, at the same time it is focused on interesting and novel topics that may improve science and literature review might be necessary. So, the research can be useful to add value to the scientific community. However, the important question here refers to who will define the priorities of the various research studies required in the country; will it be the Government of the country? The Government in cooperation with the Global Organizations? The individual research scientific centerswhich, unfortunately, is usually the case? We'll try to approach this matter later on, but before that it is reasonable to give some general aspects of the importance of life sciences and agriculture in particular in peoples' life, (through the Biometry, as the responsible science for their research).

The effect of the three biological sciences- agriculture, environment and medicine in the people's life is of the greatest importance. The chain of the influence of the environment to the form and quality of the agricultural production and the effect of both of them to the people's health and welfare consists in an integrated system that is the basic substance of the human life. Agriculture has a great importance in the World's economy; however, the available resources for research and technology development are limited. Moreover, the environmental and productive conditions are very different from one country to another, restricting the generalized transferring of technology. The statistical methods should play a paramount role to insure both the objectivity of the results of agricultural research as well as the optimum usage of the limited resources. This exact need of making the theoretical statistics applicable to biological phenomena raised the appearance of the scientific field of biometry. According to the very philosophical reality on which the main law of the International Biometric Society's (IBS) bylaws was based, it should not probably allowed to the biometricians to be proud when they talk about statistics from the theoretical point of view, but only if it refers to the sense of "bios" (meaning life). What was the result achieved up to resent years is presented in the following review.

Stergios Tzortzios ${ }^{1}$ reported that if one goes through the papers presented in the IBS conferences and the publications in the IBS journals one shall realize that in the Practical Applications of
Statistics in the biological research, and more particularly in the fields of agriculture and environment, are not more than $50 \%$ of the total, although-according to the IBS bylaws they should be nearly to $100 \%$. In the journal of "Biometrics" it is much lower. It is very strange that it is a similar case particularly in regards to the journal of JABES -which was created on the purpose of giving the solution to the problem of "Biometrics" after all those comments and suggestions made by many IBS members since some decades ago.

However, questions arise whether the today's performance of the IBS organization as an International Society offers the best possible contribution to the biological research globally. But the various calls for help in research collaboration from all the developing countries don't support this. On the contrary, urgent ascertainments on the need for changes in the methodology of teaching biometryas applied research methods and statistics in scientific sectors - and on the collaboration in the practice, are quite often outputs in IBS conferences, especially in those of the IBS Regions and Groups of the developing countries.

In the following Tzortzios ${ }^{2}$ an attempt is presented to get an idea about the research done in the last years in all the countries in the three sciences- agriculture, environment, and health-medicine, through their publications in the period from 1996 to 2013 and make the comparisons between them SJR, ${ }^{3}$ which shows the gap between the developed and developing countries and the lack of the cooperation required: In the subject area of "Agricultural and Biological Sciencesmiscellaneous" the number of publications range from 85.076 (for USA) down to 1 or 2 and up to 50 in the 110 developing countries (out of 220 in total), with the respective number of Citations per document ranging from 29 to 0 or 1 up to 5 , and the $\mathrm{H}$-Index from 287 to 0 or 1 up to 10. In the subject area of "Environmental Sciences Miscellaneous" the number of publications range from 54000 (for USA) and around 10000-20000 for five more developed countries down to $1-10$ in 140 developing countries (out of 214 in total), with the respective citations per document from some thousands or hundreds for the developed countries down to 0 or single digit numbers for developing countries. In the subject area of "Health Professions Miscellaneous" the number of publications range from some hundreds to the most developed 23 countries down to $0-50$ for the rest of the 126 countries presented No comments for the citations.

\section{A comparison between the continents for their published research}

\section{In the field of Agricultural research (Figure I)}

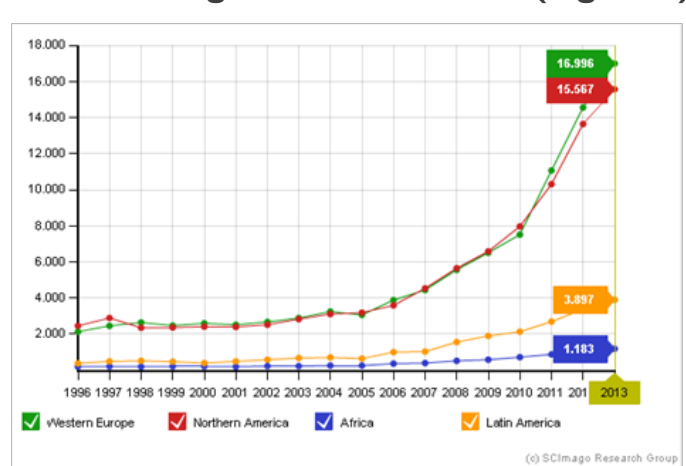

Figure I Comparison W Europe-N America-Africa-Latin America for published documents. 
In the field of Environmental research (Figure 2)

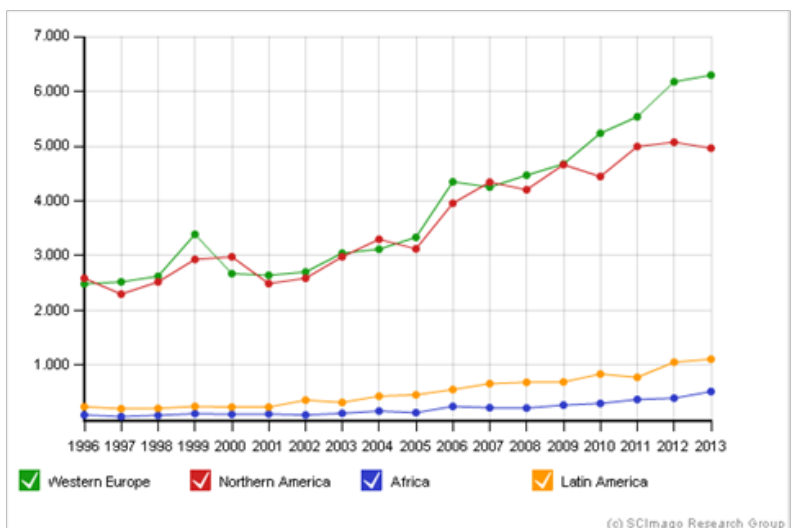

Figure 2 Comparison W Europe-N America-Africa-Latin America for published documents.

\section{In the field of Health research (Figure 3\&4)}

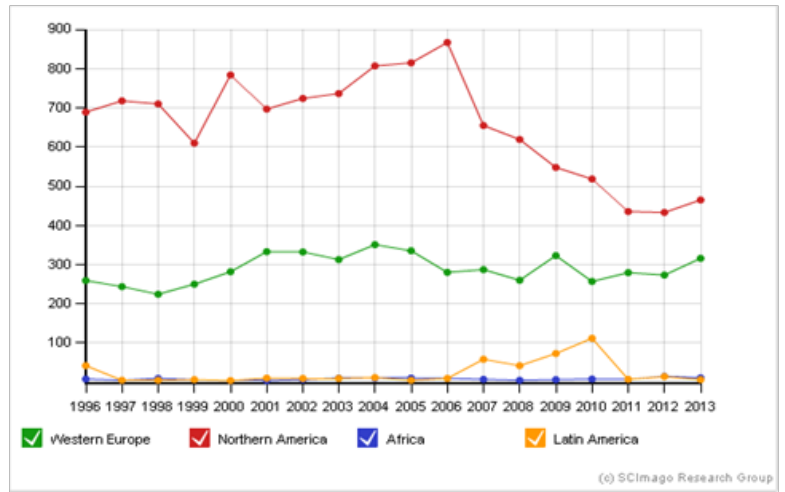

Figure 3 Comparison W Europe-N America-Africa-Latin America for published documents.

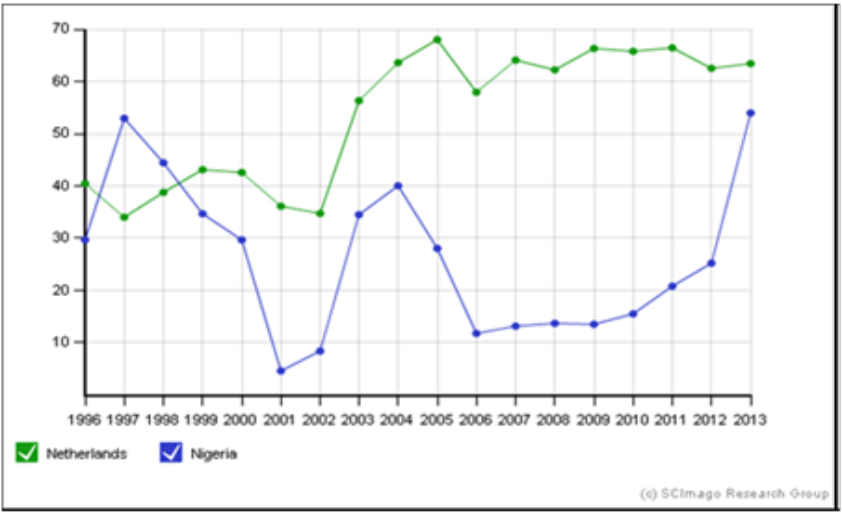

Figure 4 A Comparison between Netherlands- Nigeria for their International Collaboration (in percent of documents with more than one country).

The above figures show the great difference between the continents and more particularly between the developed and developing countries in the number of publications and their H-Index which means the quantity and the quality of the research. However, it can be emphasized that there is an increasing interest in the developing world in their collaboration with colleagues from other counties in order to increase the quantity and quality of their biological research.

\section{An effort to evaluate the biometric efficiency in the real practical situation}

Of the first problems reported in the literature is the misuse of biometrical methodologies. Regardless everyone's assessment of the as above presented review of the papers presentation it is worthwhile an effort to undertake an evaluation of the real practical situation in the agricultural industry as a whole, e.g. education-research-production.

Rilley ${ }^{4}$ reported that the literature has demonstrated in recent years that deficiencies exist in biometric approaches in developing countries. Suggestions for the improvement of biometrical services in these countries, statistics training schemes and for the supply of equipment were outlined by many authors including Nokoe, ${ }^{5}$ Lauckner, ${ }^{6}$ and others, although the need for appropriate technology was also heavily stressed as inappropriate donations of aid can actually be detrimental. Nokoe examined statistics and computing in mainly English-speaking countries of East and West Africa and concluded that available biometricians suffered from lack of funds, inadequate training facilities and isolation from peers. Nokoe also commented that because of poor university training, statisticians were often less well equipped to do good statistics than were their scientific colleagues in agriculture and forestry departments. Their approaches to biometric issues often did not relate to reality, embracing rigid theoretical methods. A major problem is a lack of appreciation of the concept of variability and why it should be estimated.

To get an idea about the biometric deficiencies in the Greek agricultural industry Tzortzios, ${ }^{7}$ has attempted a project on the "Survey and evaluation of biometric approaches in the field of agriculture" in Greece at first stage and in collaboration with other countries. A first remarkable conclusion seemed to be the notable differences between the various basic sectors of agriculture in broad sense (e.g. plant science and production, animal science and production, food technology, engineering and natural recourses, forestry, agricultural economics and management) on the following main biometrical approaches: (a) ways of Data Management, Collection, Organization and Manipulation; (b) Methods of Statistical Analysis-processing; (c) the Experimental designs used; (d) the computer equipment-Software used. It was rather expectable due to the natural differences in their subject and material from basic points of view.

Many problems also reported Tzortzios, ${ }^{2}$ on: the design of the experiments Lauckner, ${ }^{6}$ in the field and the data recording Tzortzios, ${ }^{8}$ in the analysis and interpretation of results Lowry, ${ }^{9}$ Camacho et al., ${ }^{10}$ in reporting results Finney, ${ }^{11}$ Nelson. ${ }^{12}$

\section{Education for research}

It is of a good worth to start this section with some very meaningful philosophical proverbs by very respectable people:

i. Education is the most powerful weapon which you can use to change the world. Nelson Mandela

ii. Develop a passion for learning. If you do, you will never cease to grow. Anthony J. D’Angelo 
iii. Aninvestmentinknowledgepays thebestinterest.BenjaminFranklin Education is the movement from darkness to light. Allan Bloom

Despite the problems reported in the literature for the insufficiency in the teaching statistics and its application in the biological research, it is rather easy to realize that we are not without help in this situation. Other countries and regions have gone through this same phase of development of statistical programs. The scientists in the developing countries can attempt to model growth and development after successful programs which were carried out in the developed countries. All together should start taking the advantage offered by the advances presented by the new information technologies and more particularly the computers science and the statistical packages. Tzortzios et al., ${ }^{13}$ supported the idea of the new technologies use in creating Regions Networks which could assist in transferring the known information on teaching and research within the regions countries.

In a keynote talk of the title "Biostatisticians, Biostatistical Science and the future" in EMR2005 conference Marvin Zelen ${ }^{14}$ noted: I prefer to use the term Statistical Science to describe the practice of Statistics. By Statistical Science, I mean the application of statistics, probability, mathematics and computing to advance our understanding of a subject matter field. I refer to the practitioners of Statistical Science as Statistical Scientists-not Statisticians. When the main field of application is in the biomedical sciences or agronomy we may often describe this activity as Biostatistical Science and its practitioners as Biostatistical Scientists. Nearly all of us have ready access to enormous communication and computational capabilities which were undreamed of a few decades ago. Many of us are on the Internet every day. This has changed the way we practice our science.

Ronald E LaPorte ${ }^{15}$ reported (for the "Supercourse" team): Ideally we would like to build more Master's and Ph.D. programs in developing countries. We want to double the training in statistics worldwide in the next 5 years. The reason that there is paucity is that few faculties can teach statistics. We are changing this. Our approach is simple, we have a network of over 50,000 faculty interested in global health and prevention from 174 countries. From this network we have collected 4800 top quality lectures, 75 from Nobel Prize winners. We make the lectures available in a free open source library (www.pitt.edu/super1/). We feed the lectures back to the faculty and the world, and they are then able to teach in areas that may not be their primary areas of expertise, as they have top quality, up to date lectures. We have already doubled the training of global health in the world.

The last four years, responding to an invitation by Ronald LaPorte I-the author of this paper- (as an IBS member and EMR President) had a good collaboration with Professor Ronald LaPorte and his colleagues in an effort to develop an International Library on research methodologies-the so called RMLA- as a basic source of knowledge to the young scientists-researchers of the developing countries. To this purpose we contacted the President of IBS, with our proposal to include the RMLA in the links of IBS for which we were given the IBS Commission's approval for they found the idea quite interesting. We hope it will help IBS to better offer its contribution to the improvement of the biological research globally.

Tzortzios \& Adam ${ }^{16}$ worked on creating an Integrated (interactive information) System, called AgroModel, aiming to improve the task of Biometry's courses for under- and post-graduate students and of training courses for researchers in the field of agriculture.

\section{The materials and methods required}

The AgroModel was created to provide tools for database management, data manipulation and data analysis, in order to be used initially for educational purposes and later on for research as well. The system was built using object-oriented visual languages (an integration of Visual Basic, SQL and Web development languages HTML, Java) used also for advanced programming and work with the system. In addition, based on primary agricultural educational and research needs, an appropriate database structure was created on a relational model scheme, where various plant and animal descriptive and research data were stored into database structures. The database was under continuous improvement and updates since new data and findings could be continuously added.

A such environment provides build-in tools as well as interfaces to software packages (e.g. SPSS, SYSTAT, STATISTICA) for mathematical and statistical analysis applied mainly to agricultural data, but also to any type of data online on the Web. Being in such an integrated environment, where the compatibility between the databases and various statistical packages is available, the trainee could undertake any type of statistical analysis from the simplest descriptive statistics to the most sophisticated stability statistics approaches (regression models, cluster analysis, etc.). The system comprises a flexible structure that is under continuous improvement and evolvement in order to maintain the research information up to date. The overall integrated environment obtained is the platform, which is finally to be placed on the WWW in order to provide distance-learning education on the web, making the agricultural information available for the benefit of agricultural society and any scientific society, in general.

Being in a well-organized database the scientist - teacher or student-could attempt various data manipulations in order to derive interesting specific parameters; to create new variables for various applications; to aggregate groups of certain purposes; and so on.

The practical meaning of the users' familiarization with such data handling utilities is obviously of great educational importance, because: it helps the user in developing the necessary self-confidence in approaching the material in study,

(a) It offers the chance for a better understanding of the statistical material's meaning as the unique source of any research study; and

(b) The most important- it contributes to the gradual development of the proper scientific mind as a pre-requisite of a possible more integrated form later on.

The proper use of the new Information Technology in the field of biological sciences could lead to an educational system based on a method of "Inductive Education" similar to the process of the agricultural research, which was presented in "Intagred-99" Tzortzios \& Adam. ${ }^{16}$ A version of the application could be provided in the World Wide Web for any distance learning or other educational and research purposes, incorporating various links to important electronic resources (libraries, conferences, journals, etc.), offering interested information (scientific, technical, etc.) related to agriculture and other sciences as well. 


\section{What can be done to help Africa?}

Among the first approaches probably could be the study of what was done by other countries which were in a similar situation and they have succeeded the development required. It is very reasonable to undertake a serious search on how have some countries been able to stop their people's hunger and poverty. It is to mention my personal questioning in my visit to Nigeria for the SUSAN/IBS2000, when I noticed that huge land without any cultivation for plant and animal production for the reason of serious products safety as they told me.

It is true that most of the extremely poor live in Africa. There is also extreme poverty in India, China and South America. But these countries are in an economic upswing. In Africa, however, the misery rises steadily. The International Monetary Fund (IMF) has tried for forty years with a neo-liberal economic policy (privatize state enterprises, liberalize markets, social expenditure savings) to set the economy of Africa in motion. It has the opposite effect. It has failed in Africa Jeffre Sachs. ${ }^{20}$

Jeffre Sachs ${ }^{17}$ makes concrete suggestions as to how extreme poverty can be overcome in Africa. His main finding is that Africa itself can not escape the economic hardship. The rich Western countries need to help financially and with personnel. Jeffrey Sachs has developed a concrete plan for overcoming poverty in Africa:

a. The agricultural income of the farmers could by good advice and some resources (irrigation, fertilizer, high-performance seed) can be doubled easily.

b. For the larger crop is not eaten immediately, the population growth should be stopped by a specific family counseling and the free distribution of contraceptives.

c. The funds must democratically be managed by the communities themselves so they do not disappear in the government corruption.

d. The poor countries must be freed from their debt burdens, so that they have money to overcome the poverty.

e. There must be an adequate infrastructure (schools, roads, health, and electricity).

It is important to work for the cooperation of all positive people. We need a global change. This can happen only through a global alliance of all positive forces in politics, science, religion and society. By the intensive efforts of many individuals, each in his place and within his means. Each rich western country can get a partnership to a poor country of the world. They can give money, knowledge and experts to their poor partner country. They can promote mutual tourism and cultural exchange. Step for step we can build up a better world, if we go forward with wisdom, love and good cooperation.

Each rich western country can get a partnership to a poor country of the world. They can give money, knowledge and experts to their poor partner country. They can promote mutual tourism and cultural exchange. Step for step we can build up a better world, if we go forward with wisdom, love and good cooperation.

Connect Help and Self-Help. The main solution to the world hunger problem is the principle of self-sufficiency through their-own country. Every farmer should have the right to have his own piece of land from which he can live with his family. The landless farmers have to get fertile land by the governments.
The landlords must give a portion of their land to the poor. Without land reforms, the world hunger problem cannot be solved. Some new agricultural land can also be created. This can happen by the forestation of desert areas. Deforestation must be stopped. Instead establishing mono-cultures (oil palm, biofuel) for export, each country should provide sufficient land for the population.

Small farmers in developing countries must be helped with a good advice from agricultural experts, an effective organic farming, with cooperative structures and a fair global trade. There are examples of ecological self-sufficient communities, where aid workers can be based on. That sustainable development works, proved the actor Karlheinz Böhm ${ }^{18}$ in Ethiopia. He has personally supervised four villages and collected donations in Germany. He established an organic agriculture and thus preserves an entire tract of land from starvation. It took more than a decade, but today, the villages are self-sufficient in everything necessary.

It is worth here to mention that interesting Chinese proverb which expresses its mission of "empowering people to improve the quality of their life themselves: "Give a man a fish and you feed him for a day. Teach a man to fish and you feed him for a lifetime."

\section{Discussion and suggestions}

The problems presented in the reviewed literature are too extensive and varied to have a simple and single origin and to have a magic solution. The poor statistical training and background of biological researchers are major factors responsible for the situation presented above. One of the most important causes is the teaching of statistics with too great a mathematical orientation and with emphasis on theory instead to the application to real world problems. Statistical training for biological researchers should be in the field (or laboratory) as well as in lecture rooms. In fact, Biometrics, and JABES, the journal of the International Biometric Society-IBS, are being criticized for becoming so highly specialized that much of their present content cannot be understood by most biologists.

The following suggestions could refer to many explanations in accordance with the particular issue that has been raised. It is considered to be of some help an effort to indicate those which seem to be the most important and of more widely accepted reasons:

1. It has been proven that a better collaboration between the biometric centres or university labs with the biological (agricultural, environmental, medical) researchers within each country could give the required improvement in the whole research task-from the first apprehension of the research project-the experimental design up to its publication.

2. It is the time now for the biometricians to take advantage of the new technologies in creating integrated informatics systems in organizing the huge amounts of research data in the most effective ways for teaching and research purposes.

3. To the best result of the above, the positive encouragement by the International Biometric Society-IBS could be very helpful by encouraging the IBS Regions and Groups to keep in their programmes the adaptation of all of them.

4. The Governments of all the countries (developed, developing and underdeveloped ones) should realize the task of the life sciences (and the IBS) and its importance for the Life in Earth, and offer the 
proper financial and ethical support to the direct practical research urgently, if they want to keep their people to respect them and stay in their mother countries.

5. The World Organizations, as the OECD, the United Nations, FAO and others, should realize the as above mentioned, and strongly support them, if they want to find some of the most effective ways in helping the peoples welfare-based in a safe and hygienic food production, and living under a controlled environment in a healthy life- and in overcoming the serious problems created to all the countries the waves of immigrants within the world.

6. It is easy to realize that to overcome the hunger the poor need enough land, enough money to start, enough knowledge to be successful, protection laws and a fair trade with the west. A lot of it has to do with the government in place. Many countries have a well-functioning government without massive amounts of corruption, meaning the distribution of wealth can more easily help the neediest people in society. Many countries dealing with hunger and poverty have corrupt governments who don't make any attempts to solve the problems, so nothing changes.

7. Let's try to promote the common sense. It is important to promote the common sense in the world. Without a return to the values of frugality, inner happiness, universal love and mutual aid the world cannot be saved. If egoism dominates the happiness in the world has no chance. We need a world family, which consists of many small families, and where everyone helps everyone, so it all goes well.

\section{Acknowledgements}

None.

\section{Conflicts of interest}

Author declares that there is no conflicts of interest.

\section{References}

1. Stergios Tzortzios. The philosophy of biometry as a basic tool for the improvement of global biological research. JENRM. 2015;1(2):37-43.

2. Tzortzios. The gap in the research on life sciences between the underdeveloped and developed countries and the help of the science of biometry in achieving the collaboration required. Biom Biostat Int J. 2018;7(2):125-129.
3. SJR. Scimago Journal \& Country Rank. USA: SJR; 2015.

4. Rilley J. Strengthening biometry and statistics in agricultural research. Germany: Proceeding of a CTA/University of Hohenheim workshop; 1996.

5. Nokoe S. On-farm trials: surgical or preventive approach. J Trop For Resources. 2000;15(2):93-103.

6. Lauckner FB. The Rise of Statistical Thinking 1820-1900. Princeton: University Press. 1989.

7. Tzortzios S. Invited speech: A study of the Biometric and Computer Applications in Agricultural education and research-A Greek case study. XIXth Summer School of Biometrics, organized by the Board of Biometrics of the Czech Academy of Agricultural Science, LedniceCzeck Rep; 2010.

8. SI Tzortzios. Computing procedures as important aids in organizing experimental data of many years and locations in one data base. 46th Congress of EAAP, Prague, Chech Republic. 1995.

9. Lowry SR. Use and misuse of multiple comparisons in animal experiments. Journal of Animal Science. 1992;70:1971-1977.

10. Camacho J, Carbonell E. Statistics and Agricultural Research: Problems. Agricultural Research, Production and Plant Protection. 1993;8(3):293309.

11. Finney DJ. Letter to the Editor. Biometric Bulletin. 1991;8:2-3.

12. Nelson LA. A statistical editor's viewpoint of statistical usage in horticultural science publications. Hort Science. 1989;24(1):53-57.

13. Tzortzios S. Invited speech. Biometrical Applications in AgricultureThe agony for their efficiency-Problems and perspectives. 2nd Eastern Mediterranean Region/International Biometric Society-EMR/IBS Conference. Antalya, Turkey. 2003.

14. Marvin Zelen. A keynote talk Biostatisticians, Biostatistical Science and the future. EMR/IBS2005 Conference. 2005.

15. Ronald E, LaPorte. Invited speech. Building Global Capacity in Statistics. EMR2011 Conference. 2011.

16. Tzortzios S. Adam G. Proper computer procedures (AgroModel) in plant and animal selection for research and educational purposes. Proc. of the International Workshop On Information Technology in Agricultural Education. 1999:

17. Jeffrey Sachs. The End of Poverty: Economic Possibilities for Our Time. 2005.

18. Karlheinz Bohm. Founder MfM Aid for Ethiopia \& Development. 1981. 